\title{
Diversification, Relatedness, And Firm Performance: Empirical Evidence From China
}

\author{
Wei Jiang, Zhejiang University, China \\ Chen Zhihui, Zhejiang University, China \\ Peng S. Chan, (Email: PChan@exchange.fullerton.edu), California State University - Fullerton
}

\begin{abstract}
The relationship between diversification, relatedness and performance has long been a controversial issue in mainstream strategic management research. Research in this area, however, has focused primarily on developed countries. This study argues that the conclusions drawn from developed countries may not apply to developing countries. In an investigation of 227 publicly-listed companies in China, this study found that: 1) firm scale significantly contributes to the improvement of economic performance; 2) relatedness correlates negatively with firm performance, and 3) the relationship between diversification and performance fits the "intermediate" model. This study also provided evidence to support the argument that differences do exist in the rationales between firms in developed and developing countries.
\end{abstract}

\section{Introduction}

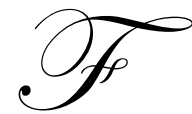

rom Chandler's (1962) pioneering work on strategy and structure to contemporary studies of the "core competence" of the corporation (Prahalad and Hamel, 1990), researchers have examined the effects of combining multiple businesses within a single organization. The relationship between the composition of a corporation's business portfolio and its economic performance has become a particularly prominent issue in strategic management research.

From a conceptual viewpoint, increasing levels of diversification should have positive effects on performance due to effects of economies of scope and scale, market power, risk reduction and learning. However, despite extensive studies on the topic, the impact of a diversified business portfolio on performance remains uncertain. "There is still considerable disagreement about precisely how and when diversification can be used to build long-run competitive advantage" (Markides and Williamson, 1994: 149). Furthermore, as suggested by Nachum (1999), the nature of diversification activity in developing countries seems to differ fundamentally from that in developed countries; hence, transferability of knowledge based on the latter to the former is limited. A few studies examining the "diversification-performance" (D-P) relationship in developing countries collected evidence to highlight the uniqueness in their diversification strategies (Lim and Teck, 1995). These studies suggest that conclusions drawn from firms in developed countries should be dealt with caution when we look at firms in developing countries. In this paper, we seek to study diversification activities and their implications for performance in developing countries. We will test hypotheses drawn from the experiences of developed countries with data collected from publicly listed firms in the People's Republic of China.

This paper is organized into four parts. The first part provides a review of recent studies on diversification strategy followed by the generation of several hypotheses regarding the performance implications of relatedness and over-diversification. The second part describes the data collection process, the construction of the regression model and the measurement of variables. The third part reports the results of the regression analysis. The final section presents our conclusion and explanation of the unique characteristics of diversification strategy in Chinese firms. 


\subsection{Theoretical Considerations and Hypotheses}

\subsection{Relatedness and performance}

In his pioneering study on diversification, Ansoff (1957) defined diversification as "the strategy to explore new market with new products." Ansoff considered diversification as one of the four generic strategies for firms to survive and develop. Later, Chandler (1962) introduced the idea of exploring patterns of diversification, which signified that different types of business portfolios might have different implications on performance. Decades later, Rumelt (1974) found that firms with interrelated business portfolios appeared to outperform firms with unrelated portfolios, independent of the type of corporate structure adopted. Rumelt concluded that firms that strictly confined their operations within their core skills and/or competences would enjoy higher growth and profitability than those that extend their business comprehensively without taking their own capabilities into account. Related diversification enhances performance through the leverage of knowledge gained in different product areas, while unrelated diversification adds administrative burden without economies of scope in developing competences.

A number of studies have lent support to Rumelt's finding (see Ramanujam and Varadarajan's synthesis, 1989), and powerful arguments for the superiority of related diversification have been advanced in the area of corporate strategy. In general, the argument is that related diversification affects firm performance through economies of scale and economies of scope (Teece, 1982), risk dispersion (Berger, 1995), and core competences building (Markides, 1994). More specifically, the theory involving the diversification-performance (D-P) linkage can be summarized as follows: first, related diversification reduces the expansion and administrative cost from the new operations, thereby achieving competitive advantage and driving up performance; and second, unused productive services are a selective force in determining the direction of expansion (Penrose, 1959). Excess resources are mostly employed in similar ways, so that firms do not diversify in a random way (Teece et al., 1994). Related diversification, in which businesses are similar with respect to resource characteristics, facilitate the sharing of manufacturing facilities, raw materials, marketing network, experience, skills and other firm-specific resources. On the one hand, the frequent transfer of knowledge and experiences among different business units would enhance innovation and efficiency, which in turn would enrich the knowledge capital pool. On the other hand, firms enjoy economies of scope by expanding into similar industries to tap excess resources. Finally, when there are redundant resources in operations that the manager cannot divest with ease, then expansion into a similar/related industry appears to be an attractive option. ${ }^{1} \quad$ Hence:

H1: Related diversification enhances firm performance.

H1a: The level of relatedness is positively correlated with performance.

H1b: Related diversifiers enjoy higher performance than their unrelated counterparts.

\subsection{Level of diversification and performance}

That there is a limit to how much a firm can diversify is a well-accepted proposition in the strategy literature. Grant et al (1988) pointed out that to a certain extent, the variation in performance and the number of businesses are positively correlated. This implies that the "D-P" relationship is not meant to be linear: while benefits accrue to diversification, at some point these efforts are also associated with major costs. Markides (1992) defined the cost of diversification as loss of control and effort (due to increased shirking), coordination cost and other diseconomies resulting from conflicting "dominant logics". Williamson (1967) concluded that the loss and/or distortion of information as it passed from one layer of a firm's hierarchy to the next created X-inefficiency that put a limit on how much a firm can grow. Empirical evidence also shows that a great number of American firms had restructured their business scope since 1980 (Lewis, 1990), and that half of them had chosen to refocus (Markides, 1995) meaning that they had reduced the number of businesses and returned to their relatively specialized domains.

Palich et al (2000) offered three different models to depict the "D-P" relationship: a linear model (Figure 1a), an inverted-U model (Figure 1b) and an intermediate model (Figure 1c). Based on a meta-analysis of fifty-five previously published studies, Palich et al provided evidence to support the curvilinear, inverted-U model, that is, firms seem to benefit from increased diversification at the beginning but tend to suffer from non-stop expansion.

${ }^{1}$ In some cases, knowledge and skills appear to exist together with the production processes and the firms themselves. This kind of knowledge is difficult to divest from the firm and will only be valuable when applied to operations. 
Based on this evidence, we can argue that the marginal cost of diversification increases rapidly as diversification reaches a high level. Thus an optimal level of diversification may exist, with performance decreasing after that point. Therefore, a moderate level of diversification would seem to be the rational choice for managers.

H2: The "D-P" relationship exhibits the "inverted-U" pattern.

H2a: A moderate level of diversification is superior to a low level of diversification in terms of firm performance.

H2b: Diversification is positively related to firm performance across the low to moderate range of diversification.

H2c: Diversification is negatively related to firm performance across the moderate to high range of diversification.

\subsection{Model, Variables and Data}

\subsection{Model construction}

To determine the effect of diversification and relatedness on firm profitability, the following model is used:

Performance $=\mathrm{f}($ Level of diversification, Scale, Relatedness $)$

This model is grounded in economic and strategic theory. The inclusion of "relatedness" is based on the theory that states that different types of diversification activities have different effects (positive or negative) on performance. The "level of diversification" is included based on the belief that variation in performance can be explained by the increased or decreased levels of diversification. Also, it is the authors' intention to examine the "pure effects" of diversification and the pattern on performance respectively.

"Scale" is introduced as the control variable. It has only been about two decades since China first moved to the market economy system. Chinese firms would by no means have fully tapped the benefits of economics of scale. Consequently, the variation in size between different companies will have significant effects on performance, which if not accounted for, may substantially affect the predictability of the other two variables.

\subsubsection{Measurement of Variables}

\subsubsection{Level of diversification}

For a firm, we calculate its entropy index of diversification using Palepu's (1985) measure, as follows:

$$
\text { Diver }_{i}=\sum_{j}^{n} p_{j} \ln \left(1 / p_{j}\right)
$$

where Diver $r_{i}$ is the level of diversification in a firm $i ; p_{j}$ is the percentage of $j^{\text {th }}$ business in the firm i's total sales, and $\mathrm{n}$ is the total number of businesses in the firm $\mathrm{i}$.

This entropy measure is one of the most widely used methods in quantifying a firm's level of diversification and is proven to have high internal reliability and good mathematical characteristics for statistical analyses (Yin, 1999). The measure is in effect a SIC-based approach, which treats businesses in the same SIC level as homogeneous and makes distinction with those in different SIC categories. Although Robins and Wiersema (1995) have criticized this underlying assumption of the entropy approach, Hall and John (1994) proved that this measure of diversification grasped the essence of business portfolio and thus had important implications for strategic management research.

To test the hypothesis of the existence of an optimal level of diversification, it was necessary to identify whether a firm was an over-diversifier or not. We followed Markides's (1994) approach in classifying firms as either refocused or not, that is, the dividing point is [mean Diver+1/2S.D.]. Using this method, we introduce a dummy variable (Dumy_overdiv) to explore the "D-P" linkage. Dumy_overdiv is labeled ' 0 ' when the level of firm diversification is less than the dividing point, otherwise it would be labeled ' 1 '.

3.2.2 Scale 
Firm revenue is one of the most widely used proxies for the size of a firm (e.g., Robins and Wiersema, 1995). The sample firms in this research are listed companies in China. These firms generate huge incomes every year. In this study, the size of the firm is operationalized as the log of revenue divided by 10 million. It is calculated as follows:

$\mathrm{SCALE}_{\mathrm{i}}=\mathrm{Ln}$ (Annual sales/ 10000000), where $\mathrm{SCALE}_{\mathrm{i}}$ is the firm i's size.

\subsubsection{Relatedness}

To measure relatedness we adopt the concentric measure developed by Montgomery and Hariharan (1991). This measure has been used by others to capture the essence of relatedness in a business portfolio. Consistent with previous researchers, the measure of relatedness is based on the SIC-code system. Based on this system, we classified all business sectors into 21 industrial groups (see Table 1). The "other" category refers to businesses that do not fall into any of the stated categories.

Consequently, the business units in the same group would have the same group code 1, otherwise the code would be 0 . Furthermore, the multiple of sales distribution is used as a weight. Thus, relatedness is calculated as follows:

$$
\text { Relate }_{\mathrm{i}}=\frac{\sum_{j} \sum_{\mathrm{k}} \mathrm{m}_{\mathrm{j}} \times n_{k} \times(0,1)}{\sum_{j} \sum_{\mathrm{k}} \mathrm{m}_{\mathrm{j}} \times n_{k}}
$$

where the $m_{j} n_{k}$ represents the percentage of sales of two business units in the firm $i ;(0,1)$ where 1 is when the two units have the same group code, otherwise, 0 .

\subsubsection{Performance}

The accounting-based measure, return on investment (ROI), is used as the indicator of firm performance. ROI is one of the most widely employed measures of performance (Hall, 1994; Markides, 1995; Palich et al., 2000). ROI is calculated as:

(Earnings before interests and taxes)/(equity + long term debt $)^{2}$.

To reduce the effects of unusually good or bad industries (i.e. the industrial interference with firms' performance), we deduct industry-weight ROI from the firm's ROI to obtain the final measure, WROI, as follows:

$$
\mathrm{WROI}_{i}=\mathrm{ROI}_{i}-\sum_{j=1}^{n} m_{k j} \times a v g_{k}
$$

where WROI $_{i}$ is the weighted ROI of firm $\mathrm{i} ; \mathrm{m}_{\mathrm{kj}}$ is the firm i's sales proportion of $\mathrm{j}^{\text {th }}$ business in industry $\mathrm{k}$; $\operatorname{avg}_{\mathrm{k}}$ is the industry k's average performance; $n$ is the total number of businesses of the firm $i$.

To obtain the average performance of each industry, the classification system presented in Table 1 is employed. Firms with the same code in an industry are grouped together, and using their sales as weight, the average ROI of every industry is estimated.

\subsection{Sample selection}

Out of the pre-defined population of 887 listed companies, which published their annual reports before April 30, 2000, we identified 235 sample firms with detailed analysis of their diversification activities and sales distribution in their reports. Although the sample was not randomly selected, the relatively large proportion of

2 There is a slight difference between the ROI we employed and the one used in the companies' annual reports. We use EBIT instead of profit to calculate ROI in order to eliminate the impact of different taxes on the firm's performance. 
sample to population (235/887) rendered the selection problem slim. In addition, PT (Particular Transfer) and ST (Special Treatment) shares were not included because of problems of heterogeneity. The number of firms in the sample pool was distributed evenly in the two listing places: 118 in Shenzhen Stock A and 117 in Shanghai Stock A respectively, which indicated that there was no problem with selection bias and that the listing place was not a factor needed to be controlled for.

Based on the results of the preliminary analysis, 8 cases were excluded because of outlier problems. Two criteria were followed for exclusion: first, firms with WROI greater than $30 \%$ above the average level of performance in the sample pool; second, firms with residual deviation greater than 3 times of standard deviation in the preliminary regression. The inclusion of these outliers was likely to distort the regression model. After the elimination, the final sample size was 227 firms comprising 115 firms in Shenzhen stock A and 112 firms in Shanghai stock A.

The null hypothesis test was conducted to determine whether the final sample was representative of the whole population (coefficients reported in Table 2). The difference between the sample and population with respect to performance (ROI) was insignificant, from which we concluded that the firms in the final pool could reflect the whole population of listed companies.

\subsection{Results and Analysis}

The descriptive statistics and correlations for all variables in the study are presented in Table 3. The low intercorrelations among variables suggested that there were no problems with multicollinearity. The only apparent high correlation for the independent variables occurred between the RELATE (level of relatedness) and SCALE (firm size) variables. Therefore, multicollinearity did not appear to represent a major problem for this study. In addition, the low correlations between independent variables together with significant correlations between independent and dependent ones (SCALE and WROI) suggested that there were sufficient independent variations among the variables employed in this study to allow discrete effects to be estimated.

The estimated coefficients regressed on the entire sample data set are reported in Table 4 . The results were somewhat a mixture of expected and unexpected outcomes. The entire model accounted for roughly $21.8 \%$ of the total variance. Although SCALE and RELATE showed some correlation in the descriptive analysis, the value of VIF (Variance Inflation Factor) and Tolerance suggested that there was no problem with multicollinearity. In addition, the value of Durbin-Watson was around 2, which indicated that there was no problem with sequential correlations. As expected, the firm's size (SCALE) and the level of relatedness among business portfolio (RELATE) both significantly correlated with the firm's economic performance. Conventional economic theories are in agreement regarding the rationales underlying a firm's efficiency boundary. Our findings indicate that the benefits of economies of scale have yet to be fully tapped by Chinese firms. Therefore, the increase in scale should boost firm performance through the benefits of economics of scale ${ }^{3}$.

However, unexpected results arose from the relationship between the level of relatedness and performance. The RELATE variable was negatively related to performance. This implies that higher levels of relatedness either makes little contribution to the performance improvement (which contradicted prior studies in strategic management) or debilitates the firm's economic output. Hypothesis 1 was therefore not supported. Perhaps prior studies have not paid sufficient attention to the adverse effects of increased levels of relatedness on performance.

Next, a regression was conducted using the dummy variable "Dumy_overdiv" to replace Diver in order to find out the performance differences between the different levels of diversity (see Table 5). Here, the regression model is constructed to serve the same purpose as that of a univariate analysis of variance model, with performance as the dependent, Dumy_overdiv as the fixed factor and SCALE and RELATE as the covariates.

As shown in Table 5, the model explained roughly $20.4 \%$ of the variance in performance (adj. $\mathrm{R}^{2}=0.204$ ), which indicated sufficient predictability and reliability. The Dumy_overdiv sign was positive but insignificant, which indicated that firms with higher levels of diversity may outperform their lower counterparts; however, the

\footnotetext{
3 This conclusion is well supported by subsequent analysis in this study. The firm size (as control variable) correlates with the firm's performance in all the regression analyses, that is, on both full and sub-sample pool.
} 
performance difference was not significant. As such, Hypothesis 2 could not be supported. Yet Palich et al (2000) argued that with the inverted $\mathrm{U}$ model of diversification-performance relationship, an optimal level of diversification exists, with performance decreases to either side of that point of maximization.

The regression results in Table 6 showed the distinctive characteristics between the two sub-sample groups divided by dummy variable, Dumy_overdiv. In the sub-sample with low levels of diversity, the level of diversity (Diver) was positively and significantly correlated with performance. However, regression on the sub-sample with higher levels of diversity did not show any clear results. Hence, it was reasonable to deduce the existence of an efficient boundary of diversification. At least, the "D-P" linkage in Chinese firms exhibited the intermediate pattern. Hypothesis 2 was therefore partially supported in that moderate levels of diversification would be a rational choice for managers to maximize profit.

\subsection{Discussion}

Kang and Ke (1999) suggested that different market backgrounds may have different implications for firms' diversification-performance relationship. They found that the level of a country's market prosperity negatively correlated with the level of firm diversification, that is, the more developed the market, the more firms chose to refocus. The cross-national comparisons in firm strategy have special implications with regard to environmental and industrial background. Similarly, Palepu (1997) pointed out that focused strategies may be wrong for emerging markets. Nachum (1999), in his investigation of developing countries, noted that to a large extent, the variety in performance can be attributed to specific characteristics of the region (e.g., the size of domestic markets) and the existence of regional economic ties. He further noted that the social cultural environment had a great impact on firms' diversification activities. Our study supported the argument that Chinese firms have managerial rationales different from that advanced by conventional economic theories.

First, the results of this study showed that firm scale positively and significantly correlated with performance. The size of the Chinese firms was relatively small and therefore they were ready to exploit the benefits of economics of scale through expansion.

Second, the significantly negative impact of relatedness on firm performance highlighted the distinctiveness in the operating rationale of firms in less developed countries, such as China. The empirical results strongly supported the positive contribution of unrelatedness to performance. This suggests that firms can enhance their performance by expanding into new, unfamiliar industries and at the same time decreasing the level of relatedness. We will attempt to explain this phenomenon in the following discussion.

\section{- $\quad$ Distinctiveness in less-developed countries}

Kang and Ke (1999) used the term "starting point principle" to describe the situation where the efficient level for firms to diversify with respect to scale is positively correlated with a nation's level of market prosperity. In China, it is less sophisticated for firms to diversify into unrelated, unfamiliar industries than their counterparts in developed countries because of the relatively low efficiency of the free market system.

Khanna and Palepu (1997) investigated the diversification activities in several developing nations and found great differences between oriental and western management rationales. Although conceived as dinosaurs in the west, large firms in emerging markets maintain substantial competitive advantage by filling out voids in governmental functions. Support systems that are taken for granted in developed nations (e.g., information services, transportation network, broadcasting system) are inadequate in developing nations. Therefore, large firms in developing countries are encouraged to enter these industries to set up their own self-support systems. The level of unrelatedness thus increases, yet performance does not seem to go down. In addition, non-market factors may also interfere with related firms' performance and conceal the negative effects of unrelatedness, such as regional protection, legal system deficiencies and the infant market mechanism.

\section{- $\quad$ Profitability and growth opportunities}

Stimpert, et al. (1997) argued that firms operating in industries characterized by low profitability and low growth opportunities tended to expand by entering into new businesses. Hence, diversification is a means of 
escaping from less profitable industries. Moreover, in a rapid growth market like China, new industries and expansion opportunities are cropping up almost on a daily basis. All firms, no matter startups or "veterans", are placed at the same starting point when they enter those newly opened industries. So both large and small firms are encouraged to invest their resources in expansion with the hope of better profitability. Furthermore, because of the vast market potential of the new businesses, the risks of expanding into unrelated markets are relatively low. By moving quickly, the firm can also tap the benefits of "first mover" advantage.

\section{- $\quad$ Cost and benefit dynamics}

Jones et al's (1998) research indicates that there are not only benefits but also costs pertaining to related diversification. The frequent exchanges of ideas, personnel and skilled employees between two related business units are likely to add to administrative costs. Consequently, performance may decrease when relatedness reaches a high level. As such, the famous management slogan of "sticking to the knitting" may well be a hidden trap.

Although we cannot develop convincing logic to explain the positive contribution of unrelatedness, some recent research on this issue suggested that we should take a fresh look at the essence of relatedness and its implications for performance. These studies describe how relatedness may interfere with firm performance, and that performance is not a guaranteed result of increased relatedness. However, these are all qualitative studies which have not been empirically supported.

Finally, contrary to Hall's (1994) study, we found that the "D-P" linkage exhibited the intermediate model in Chinese listed firms. Diversification can be tied to the notion that it will yield positive but diminishing contribution to performance beyond some point of optimization. Observations show that many industries in China have low entry barriers and high growth potential that persuade managers to expand into new businesses. Therefore, the risk of diversifying into different industries is outweighed by the expectation for future yield. In addition, Khanna and Palepu (1997) noticed the lack of support systems in developing countries, such as communication infrastructure. The rational choice for large firms, therefore, is to diversify into those industries to fill up the voids of government and to develop a brand to spread the cost of maintaining it across multiple lines of business.

\subsection{Conclusion and Implications}

In this study, we analyzed 227 Chinese listed companies in order to investigate the D-P linkage in the context of a less-developed country. The most important and interesting finding of this study is that the level of relatedness negatively correlates with firm performance after some firm-specific variables are controlled for. We attribute this finding to three arguments: the distinctive nature of markets in less-developed countries, profitability and growth opportunities, and finally, cost and benefit dynamics. These three arguments appear to shed light on the D-P linkage in emerging markets and help us understand firm behavior in these markets.

Consistent with prior findings regarding the relationship between firm size and performance, we found strong support for the positive contribution of large firm size to economic output. This implies that Chinese firms have yet to fully tap the benefits of economics of scale and that scale expansions do help to improve performance. Regarding the level of diversification, the results from the Chinese firms suggested that an optimal level of diversification exists, that is, once diversification reaches the optimal point it will have diminishing effects on performance.

In sum, this study questioned the generalizability of existing economic theories drawn from developed countries. It has shown that in the case of an emerging country like China, the nature and characteristics of the relatedness-performance linkage, the diversification-performance linkage and the benefits of economics of scale are quite different from those of developed countries.

\section{References}

1. Ansoff, H.I. (1965), Corporate strategy, Homewood, IL: Dow Jones-Irwin.

2. Berger, P. G. and E. Ofed (1995), "Diversification's effect on firm value", Journal of Financial Economics, 37, 
pp. 39-65

3. Doukas, J. A., Martin Holmén and Nickolaos G. Travlos (2001), Corporate Diversification and Firm Performance: Evidence from Swedish Acquisitions

4. Farjoun, M. (1998), "The independent and joint effects of the skill and physical bases of relatedness in diversification", Strategic Management Journal, Vol.19, pp.611-930

5. Grant, R. M., A. P. Jammine and H. Thomas (1988), "Diversity, diversification, and profitability among British manufacturing companies, 1972-84", Academy of Management Journal, 31(4), pp. 771-801

6. Hall, E. H. Jr (1994), "A methodological note on diversity measurement", Strategic Management Journal, Vol.15, pp.153-168

7. Jones, G. R. and C. W. L. Hill (1988), "Transaction cost analysis of strategy-structure choice", Strategic Management Journal, 9(2), pp.159-172

8. Khanna, T. and Krishno Palepu (1997), "Why focused Strategies May Be Wrong for Emerging Markets", Harvard Business Review, July-August, pp.41-51

9. Lewis, W. W. (1990), "Strategic restructuring: A critical requirement in the search for corporate potential”, In M. L. Rock and R.H. Rock (eds.), Corporate Restructuring, McGraw-Hill, New York, pp. 43-55

10. Lim, G.E., Teck, T.Y., 1995, "Diversification strategies, firm characteristics and performance among Singapore firms", International Journal of Management, 12(2), pp.223-233

11. Markides C. C. (1992a), "The consequences of corporate refocusing: Ex-ante evidence", Academy of Management Journal, 35(2), pp.398-412

12. Markides C. C. (1995), "Diversification, Restructuring and economic performance", Strategic Management Journal, Vol.16, pp.101-118

13. Markides, C. C. and P. J. Williamson (1994). "Related Diversification, Core Competence and Corporate Performance", Strategic Management Journal, Vol. 15, pp.149-165

14. Nachum, L. (1999), "Diversification strategies of developing country firms", Journal of International Management, Vol.5 pp.115-140

15. Palepu, K. (1985), "Diversification strategy, profit performance and the entropy measure", Strategic Management Journal, 6(3), pp. 239-255

16. Palich L. E., Cardinal L. B. and Miller C.C.(2000), "Curvilinearity in the diversification-performance linkage: An examination of over three decades of research", Strategic Management Journal, Vol. 21, pp. 155-174

17. Ramanujam. V., P. Varadarajan (1989), "Research on corporate diversification: A synthesis", Strategic management journal, 10(6), pp.523-552

18. Reed, R. (1991), "Bimodality in diversification: An efficiency and effectiveness rationale", Managerial and Decision Economics, 12, pp. 57-66

19. Rumelt, R. P. (1974), Strategy, structure and economic performance, Harvard University Press, Cambridge, MA

20. Stimpert, J. L., and I. M. Duhaime, (1997), "Seeing the big picture: The influence of industry, diversification, and business strategy on performance". Academy of Management Journal: 40: pp.560-583

21. Teece D. J. (1982), "Towards and economic theory of the multiproduct firm", Journal of Economic Behavior and Organization, 3, pp. 39-63

22. Teece D. J., Rumelt, R., Dosi, G., Winter, S., 1994, "Understanding corporate coherence: theory and evidence", Journal of Economic Behavior, pp.23,1-30

23. Wernerfelt, B. and C. A. Montgomery (1988), "Tobin's q and the importance of focus in firm performance", American Economic Review, 78, pp.246-250

24. Williamson, O. E. (1967), "Hierarchical control and optimum firm size", Journal of Political Economy, 75(2), pp.123-138

25. Kang R.P., and Ke Y.B. 1999, Review on Chinese Firms: Strategy and Practice, Enterprise Management Press.

26. $\quad$ Kang R.P., and Ke Y.B. 1999. Firm's Diversification Business. Economic Science Press.

27. Yin Y.S. 1999 Moderate Diversification: Firm's Growth and Business Restructuring, Sanlian Bookstore Press.

Figure 1: Three models of D-P linkage

Performance

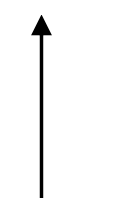

Performance

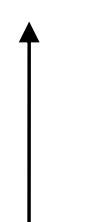

8

Performance 
Table 1: Industrial classification group

Table 1: Industrial Classification Group

\begin{tabular}{|c|l|c|l|}
\hline Group code & \multicolumn{1}{|c|}{ Description } & Group code & \multicolumn{1}{|c|}{ Description } \\
\hline & & & \\
\hline $\mathbf{1}$ & Banking & $\mathbf{1 1}$ & Tourism \\
\hline $\mathbf{2}$ & Real estate & $\mathbf{1 2}$ & Instrument and meter \\
\hline $\mathbf{3}$ & Petrochemical & $\mathbf{1 3}$ & Automobile, motorcycle (vehicle) and related fittings \\
\hline $\mathbf{4}$ & Public utilities & $\mathbf{1 4}$ & $\begin{array}{l}\text { Information \& technology (software, communication, } \\
\text { etc.) }\end{array}$ \\
\hline $\mathbf{5}$ & Electronics (household appliances, & $\mathbf{1 5}$ & $\begin{array}{l}\text { Construction (capital construction, project contract, } \\
\text { etc.) }\end{array}$ \\
\hline $\mathbf{6}$ & Plectronic wares, etc.) & $\mathbf{1 6}$ & Textile and costume \\
\hline $\mathbf{7}$ & Mechanism & $\mathbf{1 7}$ & Hotel, restaurant and related services \\
\hline $\mathbf{8}$ & Construction materials & $\mathbf{1 8}$ & Food, drink, sugar, tobacco and wine \\
\hline $\mathbf{9}$ & Metallurgy and industry material & $\mathbf{1 9}$ & Agriculture and related products \\
\hline $\mathbf{1 0}$ & Commerce, wholesale and retail & $\mathbf{2 0}$ & Transportation (harbor, airport, etc.) \\
\hline $\mathbf{2 1}$ & Other & & \\
\hline
\end{tabular}

Table 2: Single Sample T test

\begin{tabular}{|c|c|c|c|c|c|c|}
\hline \multicolumn{9}{|c|}{ Population size $=887$; Population average= 0.1355} \\
\hline Test variable & \multirow{2}{*}{$\mathrm{T}$} & Df & Sig. (two tail) & $\begin{array}{c}\text { Average } \\
\text { difference }\end{array}$ & 95\% Confidence Interval of the Difference \\
\cline { 5 - 7 } & & & .318 & $6.105 \mathrm{E}-03$ & $-5.9246 \mathrm{E}-03$ & Upper \\
\hline ROI & 1.000 & 226 & $.314 \mathrm{E}-02$ \\
\hline
\end{tabular}

Notes: $\mathrm{N}=22$; Sample average $=0.1416$

Table 3: Correlation Coefficients Matrix (Pearson correlations)

\begin{tabular}{|l|cccccc|}
\hline Variables & Means & S.D. & 1 & 2 & 3 & 4 \\
\hline 1.WROI & 0.0174 & 0.094 & 1.000 & & \\
2.Diver & 0.9290 & 0.3734 & 0.110 & 1.000 & \\
\cline { 3 - 6 } & & & &
\end{tabular}




\begin{tabular}{|c|cccccc|}
\hline 3.SCALE & 3.7883 & 1.085 & $0.428 * *$ & 0.085 & 1.000 & \\
4.RELATE & 0.3690 & 0.3742 & -0.089 & 0.087 & $0.182 * *$ & 1.000 \\
$\mathrm{~N}$ & & & 227 & 227 & 227 & 227 \\
\hline
\end{tabular}

Notes: **Correlation is significant at the 0.01 level (2-tailed);

$*$ Correlation is significant at the 0.05 level (2-tailed).

Table 4: Full Sample Regression (Dependent=WROI)

\begin{tabular}{|c|cc|c|c|c|cc|}
\hline & $\begin{array}{c}\text { Unstandardized } \\
\text { Coefficients }\end{array}$ & Std. Error & $\begin{array}{c}\text { Standardized } \\
\text { Coefficients }\end{array}$ & $\mathrm{T}$ & Sig. & \multicolumn{2}{c|}{$\begin{array}{c}\text { Collinearity Statistics } \\
\text { Tolerance }\end{array}$} \\
\hline (Constant) & $-7.535 \mathrm{E}-03$ & .023 & & -.328 & .743 & & \\
SCALE & $4.106 \mathrm{E}-02$ & .005 & .484 & 8.075 & .000 & .962 & 1.039 \\
Diver & $4.508 \mathrm{E}-03$ & .015 & .018 & .309 & .757 & .988 & 1.013 \\
RELATE & $-2.868 \mathrm{E}-02$ & .015 & -.117 & -1.946 & .053 & .962 & 1.040 \\
\hline \hline & $\mathrm{N}=227$ & $\mathrm{R}^{2}=0.229$ & adj. $\mathrm{R}^{2}=0.218$ & $\mathrm{~F}=22.060$ & $\mathrm{P}=0.000$ & \multicolumn{2}{c|}{ Durbin- } \\
Watson=2.126
\end{tabular}

Table 5: Whole Sample Regression, The Extent Of Diversification (Dependent=WROI)

\begin{tabular}{|c|cc|c|c|c|cc|}
\hline & $\begin{array}{c}\text { Unstandardized } \\
\text { Coefficients }\end{array}$ & Std. Error & $\begin{array}{c}\text { Standardized } \\
\text { Coefficients }\end{array}$ & $\mathrm{T}$ & Sig. & \multicolumn{2}{c|}{ Collinearity Statistics } \\
\hline Tolerance & VIF \\
SCAnstant) & -.117 & .020 & & -5.767 & .000 & & \\
RELATE & $3.882 \mathrm{E}-02$ & .005 & .449 & 7.340 & .000 & .940 & 1.063 \\
Dumy_overdiv & $-4.424 \mathrm{E}-02$ & .015 & -.177 & -2.919 & .004 & .962 & 1.039 \\
\hline \hline & $1.194 \mathrm{E}-02$ & .012 & .059 & .983 & .327 & .963 \\
\hline
\end{tabular}

Table 6: Sub-Sample Regression, The Extent Of Diversification (Dependent=WROI)

\begin{tabular}{|c|c|c|c|c|c|c|c|}
\hline \multirow{2}{*}{ Dumy_overdiv $=0$} & \multirow{2}{*}{\multicolumn{2}{|c|}{$\begin{array}{c}\text { Unstandardized } \\
\text { Coefficients }\end{array}$ Std. Error }} & \multirow{2}{*}{$\begin{array}{l}\text { Standardized } \\
\text { Coefficients }\end{array}$} & \multirow[b]{2}{*}{$\mathrm{T}$} & \multirow{2}{*}{ Sig. } & \multicolumn{2}{|c|}{ Collinearity Statistics } \\
\hline & & & & & & Tolerance & VIF \\
\hline (Constant) & -.184 & .030 & & -6.031 & .000 & & \\
\hline SCALE & $4.819 \mathrm{E}-02$ & .006 & .559 & 8.014 & .000 & .951 & 1.051 \\
\hline Diver & 4.077E-02 & .024 & .119 & 1.726 & .086 & .979 & 1.022 \\
\hline \multirow[t]{2}{*}{ RELATE } & $-3.744 \mathrm{E}-02$ & .017 & -.153 & -2.216 & .028 & .971 & 1.030 \\
\hline & $\mathrm{N}=155$ & $\mathrm{R}^{2}=0.302$ & $\operatorname{adj} . R^{2}=0.286$ & $F=21.798$ & $\mathrm{P}=0.000$ & \multicolumn{2}{|c|}{$\begin{array}{c}\text { Durbin- } \\
\text { Watson=1.891 }\end{array}$} \\
\hline Dumy_overdiv $=1$ & $\begin{array}{l}\text { Unstandardized } \\
\end{array}$ & Std. Error & "Standar & $\mathrm{T}$ & Sig. & \multicolumn{2}{|c|}{$\begin{array}{l}\text { Collinearity } \\
\text { Tolatistics } \\
\text { Tolence VIF }\end{array}$} \\
\hline (Constant) & $-8.921 \mathrm{E}-03$ & .097 & & -.092 & 927 & & \\
\hline SCALE & $1.947 \mathrm{E}-02$ & .011 & .218 & 1.834 & .071 & .954 & 1.048 \\
\hline Diver & $-7.523 \mathrm{E}-03$ & .071 & -.01 & -.106 & .916 & .919 & 1.088 \\
\hline RELATE & $-6.156 \mathrm{E}-02$ & .032 & -.234 & -1.944 & .056 & .924 & 1.083 \\
\hline \multicolumn{2}{|r|}{$\mathrm{N}=72$} & $\mathrm{R}^{2}=0.086$ & $\operatorname{adj} . R^{2}=0.046$ & $\mathrm{~F}=2.146$ & $\mathrm{P}=0.000$ & \multicolumn{2}{|c|}{$\begin{array}{c}\text { Durbin- } \\
\text { Watson=2.006 }\end{array}$} \\
\hline
\end{tabular}

